\title{
Eating Disorder Severity and Psychological Morbidity in Adolescents with Anorexia Nervosa or Atypical Anorexia Nervosa and Premorbid Overweight/Obesity
}

Abigail Matthews ( $\nabla$ abigail.matthews@cchmc.org )

Cincinnati Children's Hospital Medical Center https://orcid.org/0000-0002-1548-2589

Rachel A. Kramer

Cincinnati Children's Hospital Medical Center

\section{Laurie Mitan}

Cincinnati Children's Hospital Medical Center

\section{Research Article}

Keywords: Anorexia Nervosa, Atypical Anorexia Nervosa, Adolescents, Overweight/Obesity, Psychological Morbidity, Weight Stigma

Posted Date: February 18th, 2021

DOl: https://doi.org/10.21203/rs.3.rs-210417/v1

License: () (i) This work is licensed under a Creative Commons Attribution 4.0 International License. Read Full License

Version of Record: A version of this preprint was published at Eating and Weight Disorders - Studies on Anorexia, Bulimia and Obesity on March 22nd, 2021. See the published version at https://doi.org/10.1007/s40519-021-01168-7. 


\section{Abstract}

Purpose

A significant proportion of adolescents with anorexia nervosa (AN) or atypical anorexia nervosa (AAN) experience premorbid overweight/obesity, yet distinct characteristics among this subset of patients remain unclear. This study examined eating disorder (ED) symptom severity, psychological morbidity, and weight stigma in patients with premorbid overweight/obesity as compared to patients with premorbid normal weights.

\section{Methods}

Participants included adolescents with AN or AAN (aged 12-18) who received multidisciplinary treatment at a pediatric medical center in the United States. ED symptoms, anxiety, and depression were compared among patients with premorbid overweight/obesity $(n=43)$ and premorbid normal weights $(n=$ 63). Associations between weight stigma, ED severity, and psychological morbidity were also examined.

\section{Results}

Patients with premorbid overweight/obesity reported greater ED severity $(p=.04)$, anxiety $(p<.003)$, depression $(p=.02)$, and a higher frequency of weight-based teasing by peers $(p=.003)$ and parent weight talk about their own weights $(p<.001)$. Weight-based teasing was positively associated with ED symptoms, anxiety, and depression for all patients, regardless of premorbid weight status.

\section{Conclusions}

Adolescents with AN or AAN and a history of overweight/obesity may present with greater ED symptom severity and psychological morbidity than patients with normal weight histories. Distinct prevention and treatment interventions for adolescents with AN or AAN and premorbid overweight/obesity may be warranted.

Level of Evidence

Level III, case-control analytic study

\section{Introduction}

Research suggests that up to one-third of adolescents with anorexia nervosa (AN), atypical anorexia nervosa (AAN), or prior to DSM-5 [1], eating disorder not otherwise specified with dietary restriction (EDNOSDR), have a history of overweight or obesity [2 - 4]. Compared to patients with premorbid normal weights, those with a history of overweight/obesity and AN/AAN or EDNOS-DR are more likely to present for treatment at a categorically normal body mass index (BMI), yet following a greater percent weight loss [2 4]. Further, this subset of patients often presents with similar or more severe physical complications of their ED than those with premorbid normal weights $[2,4,5]$, likely reflecting findings that total percent weight loss 
predicts physical sequelae in EDs [5, 6]. Of grave concern, adolescents with AN/AAN or EDNOS-DR and a history of overweight/obesity are more likely to experience diagnostic delays $[3,4,7]$, which is a negative prognostic factor in ED recovery [8] and are less likely to be medically hospitalized for physical sequelae [2].

To our knowledge, ED symptom severity and psychological morbidity among adolescents with AN/AAN and premorbid overweight/obesity remains understudied. In a sample of females with various EDs, Swenne (2016) found commensurate ED symptomatology and depression for patients with premorbid BMls in the normal, overweight, and obesity ranges [9]. However, the diverse diagnostic sample in Swenne's study precludes the generalizability of these findings to youth with AN/AAN. Prior research has also compared adolescents with AN or AAN, thus examining the association between presenting BMI and clinical characteristics across diagnoses. In these studies, adolescents with AAN have demonstrated similar or greater ED symptom severity than AN counterparts and similar levels of psychological comorbidity $[7,9$, 10]. Since a significant proportion of adolescents with AAN experience overweight/obesity prior to illness onset [7], similar trends could exist in AN/AAN across premorbid BMI classes. Weight suppression could also account for differences in ED symptomatology and mental health symptoms in adolescents with AN/AAN, independent of premorbid weight status. Weight suppression (WS) is defined as the difference between an adult's highest premorbid and presenting weights and, in youth, the difference between premorbid and presenting BMI percentiles to account for growth $[11,12]$. Whereas a positive association between WS, ED symptom severity, and psychological distress has been evidenced in adults with EDs [13, 14], the impact of WS on psychological characteristics remains understudied in adolescents.

For adolescents with AN/AAN and premorbid overweight/obesity, historical weight stigmatizing experiences, coupled with extant reinforcement for weight loss could perpetuate ED symptom severity and psychological comorbidities, potentially exceeding that experienced by adolescents with premorbid normal weights [15]. Growing rates of overweight/obesity have prompted widespread initiatives to mitigate the "obesity epidemic" that though well-intentioned, can inadvertently perpetuate weight stigma among adolescents $[16,17]$. Whereas weight loss may be medically indicated to optimize health among youth with overweight/obesity, it remains unclear how these messages are internalized and to what extent they impact engagement in disordered eating behaviors [18]. Further, youth today are inundated with sociocultural messages that glorify thinness, promote dieting, and assert that obesity is always a dangerous health condition [19 - 22]. Lastly, weight stigma has consistently been associated with adverse physical, psychological, and social outcomes, and is an identified risk factor for ED development [23 - 25].

The primary aim of this study was to assess ED symptom severity and psychological morbidity among the subset of adolescents with AN/AAN and a history of overweight/obesity, as compared to adolescents with AN/AAN and premorbid normal weights. We also aimed to examine the association between weight stigma, ED symptoms, and psychological morbidity in adolescents with AN/AAN. We were particularly interested in weight-based teasing and parent weight talk, as these experiences are more prevalent among adolescents with overweight/obesity [26 - 28] and have been associated with ED behaviors and poorer mental health $[26,29-32]$. We hypothesized that adolescents with AN/AAN and premorbid overweight/obesity would report greater ED symptomatology and psychological morbidity than premorbid normal weight counterparts, and that these symptoms would be positively associated with weight-based teasing and 
parent weight talk. Findings from this study could offer novel insights about the subset of adolescents with AN/AAN and premorbid overweight/obesity that could guide distinct prevention and treatment efforts.

\section{Methods}

Patients were identified via retrospective chart review and included 106 adolescents (aged 12-18), newly diagnosed with AN or AAN at a large pediatric medical center in the Midwestern United States between July 2017 and December 2019. All patients received specialized ED treatment within a multidisciplinary outpatient program ( $n=30 ; 28.3 \%$ of total sample) or while medically hospitalized for acute complications of AN or AAN ( $n=76 ; 71.7 \%$ of total sample). Forty-four patients in our sample (41.5\%) met DSM-5 diagnostic criteria for AN [1] and 62 patients (58.5\%) met criteria for AAN, as defined by DSM-5 criteria for AN, apart from being categorically underweight (i.e., percent median body mass index (\%mBMI) for ageand-sex $\leq 15^{\text {th }}$ percentile) [33]. Patients were classified by premorbid weight class, as defined by the Center for Disease Control [33], with \%mBMI $\geq 95^{\text {th }}$ representing obesity; \%mBMI $\geq 85$ th but $<95^{\text {th }}$ representing overweight; and $\% \mathrm{mBMl}<85^{\text {th }}$ percentile representing normal weight. Approximately $40 \%$ of our sample experienced premorbid overweight/obesity $(n=43)$, including 21 patients with premorbid overweight $(19.8 \%$ of total sample) and 22 patients with premorbid obesity ( $20.8 \%$ of total sample). Sixty-three participants $(59.4 \%)$ in our sample were of premorbid normal weight status. No patients in our sample were of premorbid underweight status. Premorbid \%mBMI was determined via electronic chart review, representing the highest electronically recorded weight and height values that individuals had ever reached. Notably, at our institution, patients' electronic medical records (EMRs) include growth data from past visits within our institution, as well as growth data obtained from community-based providers with compatible EMR platforms. Further, for patients seen within our ED program who have limited historical growth data in their EMRs, we request paper growth records from past providers, and all acquired data is hand-entered into EMRs. Thus, historical growth data is often comprehensive and facilitates a clear picture of premorbid growth for patients. As such, in our study, comprehensive growth data was available for $92.5 \%$ of patients $(n=98)$. For 8 patients $(7.5 \%$ of total sample), premorbid weights were obtained via patient and/or caregiver self-report.

All patients completed a comprehensive psychosocial battery at treatment outset, in line with standard clinical care within our institutional ED program, and parents completed a brief demographic questionnaire. This study was approved by the Institutional Review Board and informed consent and assent were obtained from all patients and caregivers.

\section{Medical chart review}

The following variables were extracted from electronic medical records (EMRs): patient age at intake, sex, ED diagnosis (AN or AAN), intake weight $(\mathrm{kg})$ and height $(\mathrm{cm})$, intake \%mBMl, intake BMI z-score (BMIz), highest premorbid weight $(\mathrm{kg})$ and height $(\mathrm{cm})$, highest premorbid \%mBMl, highest premorbid BMlz, illness duration (months), and care status (inpatient or outpatient). Percent weight loss was calculated by subtracting intake weight from premorbid weight, dividing by premorbid weight, and multiplying by 100 . 
Weight suppression (WS) was calculated by subtracting intake BMlz from highest premorbid BMIz, in line with Accurso and colleagues [11].

\section{Psychosocial assessment battery}

\section{Eating disorder symptoms}

ED symptom severity was assessed with the Eating Disorder Examination-Questionnaire (EDE-Q) [34]. The EDE-Q Global score and the four EDE-Q subscale scores, Restraint, Shape Concern, Weight Concern, and Eating Concern, were used in analyses with higher scores indicating greater ED symptom severity. The EDE$Q$ is widely used in research with male and female adolescents diagnosed with ED with diagnoses of AN or AAN [35 - 38]. The EDE-Q is considered to have acceptable validity and reliability among adolescents [39].

\section{Psychological symptoms}

Symptoms of depression and anxiety were measured with the Total Anxiety and Major Depression scales of the Revised Child Anxiety and Depression Scale (RCADS) [40]. The RCADS is noted to have adequate factorial, convergent, and discriminant validity among clinical samples [41] and acceptable reliability [42]. Percentile scores for age and sex were calculated for each scale and used in analyses.

\section{Weight-based teasing and parent weight talk}

The frequency of historical weight-based teasing was assessed with three items rated on a 5-point Likert scale ranging from 1 ("never") to 5 ("all of the time"), including "How often have other kids teased you about your weight?", "How often have your parents teased you about your weight?", and "How often have your siblings teased you about your weight?" Two additional items assessed the frequency of parent weight talk with the same 5-point Likert scale, including "How often have your parents commented about your weight?" and "How often do(es) your parent(s) make comments about their own weight(s)?" Individual items were assessed separately in analyses.

\section{Parent BMI}

Parent weight and height were self-reported on the demographic questionnaire and were used to calculate parent BMI. Per CDC guidelines [27], parent BMI $\geq 25.0$ was classified as overweight/obesity, parent $\mathrm{BMI} \geq$ 18.5 but $<25.0$ represented normal weight status, and parent $\mathrm{BMI}<18.5$ represented underweight status.

\section{Statistical analyses}

Data was analyzed using SPSS version 25.0 and can be summarized into four categories: 1) demographics, 2) ED symptoms, anxiety, and depression, 3) weight-based teasing and parent weight talk and 4) associations between ED symptoms, anxiety, depression, weight-based teasing, and parent weight talk. In the first category, demographic variables were analyzed for patients with premorbid overweight/obesity and premorbid normal weight, including age, sex, diagnosis, intake \%mBMI, intake BMlz, premorbid \%mBMI, premorbid BMIz, percent weight loss, WS, care status, and parent BMI. Differences 
across groups were assessed using Chi Square and Fisher's Exact Tests (when cell counts were five or less) among nominal variables and $t$-tests among continuous dependent variables. For the second category ANCOVAs and a MANCOVA were run to assess clinical characteristics across premorbid weight categories. To assess differences between percentile scores (gender-specific) on RCADS Anxiety and RCADS Depression, ANCOVA controlling for care status and WS were run. To assess ED symptoms, a MANCOVA was run to assess differences between premorbid weight categories on Restraint, Shape Concern, Weight Concern, and Eating Concern, given significant correlations between EDE-Q subscale scores. Further, an ANCOVA was run to assess overall ED symptoms (EDE-Q Global). Sex, care status, and WS were included as covariates given identified sex differences in ED symptoms [43] and to control for potential differences associated with medical status. Weight suppression was also included as a covariate given substantive research supporting the association between WS and ED symptom severity $[11,12]$. Differences in ED symptoms, anxiety, and depression among individuals with AN versus AAN were also assessed to further clarify findings related to premorbid weight status and outcome variables. The third category of analyses compared patients with premorbid overweight/obesity to patients with premorbid normal weight status on frequency of prior weight-based teasing (by peers, parents, siblings) and parent weight talk (about the parent's weight, about the patient's weight) using Mann-Whitney Independent Samples U-Tests. MannWhitney $\mathrm{U}$ tests were also conducted to assess associations between parent weight talk and parent weight status determined by parent BMI. Category four consisted of analyses that examined the impact of weightbased teasing and parent weight talk on ED symptoms, anxiety, and depression using partial Spearman correlations (i.e., controlling for premorbid weight status).

\section{Results}

\section{Demographic characteristics of adolescents with AN/AAN and premorbid overweight/obesity versus adolescents with AN/AAN and premorbid normal weight status}

The demographic characteristics of patients with premorbid overweight/obesity were compared to patients with premorbid normal weight status and are summarized in Table 1. There were no significant differences in age $(p=.10)$, care status $(p=.83)$, WS $(p=.11)$, or illness duration $(p=.14)$. Compared to patients with premorbid normal weights, patients with premorbid overweight/obesity had significantly higher premorbid and presenting \% $\mathrm{mBMI}$ and BMIz scores (all $p s<.001$ ), were more likely to be diagnosed with AAN versus AN $(p=.002)$, had a greater percent weight loss, even after controlling for illness duration $(p<.001)$, and were more likely to be male $(p=.01)$. Parent BMI was significantly higher among patients with premorbid overweight/obesity $(p=.04)$.

\section{ED symptoms, anxiety, and depression}

Results indicated that patients with premorbid overweight/obesity reported significantly higher scores on the EDE-Q Restraint subscale $(F(1,103)=4.27, p=.04)$, the EDE-Q Shape Concern subscale $(F(1,103)=$ $5.13, p=.03)$, the EDE-Q Weight Concern subscale $(F(1,103)=5.59, p=.02)$, and the EDE-Q Global scale $(F(1,103)=4.19, p=.04)$ after controlling for sex, care status and WS. Patients with premorbid overweight/obesity reported significantly higher anxiety (RCADS Anxiety, $F(1,103)=9.46, p=.003)$, and 
depression (RCADS Depression, $F(1,103)=5.74, p=.02)$ after controlling for care status and WS. There were no significant differences in EDE-Q Global and subscale scores, RCADS Anxiety, or RCADS Depression for diagnosis (AN versus AAN; all ps > .05).

\section{Weight-based teasing and parent weight talk}

The frequency of weight-based teasing and parent weight talk among patients with premorbid overweight/obesity and patients with premorbid normal weight is detailed in Table 3. Analyses indicated patients with premorbid overweight/obesity reported a higher frequency of weight-based teasing by peers ( $z$ $=3.58, p<.001)$ and parent comments about their own weight $(z=3.29, p=.001)$ than patients with premorbid normal weight status. Further, parent BMI was significantly associated with patients' perceived frequency of parent comments about their own weight. Parents who had overweight/obesity were reported to make more frequent comments about their weight $(z=2.49, p=.01)$. There were no significant differences in the frequency of weight-based teasing by siblings, weight-based teasing by parents, or parent weight talk about patient weights for premorbid weight status (all $p s>.05$ ).

\section{Associations between ED symptoms, anxiety, depression, weight-based teasing, and parent weight talk}

Partial Spearman correlations (controlling for premorbid weight status) indicated the frequency of weightbased teasing by peers was significantly correlated with ED symptom severity (EDE-Q Global: $r=.24, p=$ .02), EDE-Q Eating Concern ( $r=0.30, p=.003)$, EDE-Q Shape Concern $(r=.27, p=.008)$, EDE-Q Weight Concern $(r=.21, p=.04)$, anxiety (RCADS Anxiety: $r=.26, p=.009$ ), and depression (RCADS Depression: $r=$ $.22, p=.03)$. Further, weight-based teasing by siblings was significantly associated with EDE-Q Eating Concern $(r=.27, p=.008)$. With respect to parent weight talk, parent comments about patients' weights were not associated with ED symptom severity, anxiety, or depression (all $p s>.05$ ). Lastly, parent comments about their own weight were associated ED symptom severity (EDE-Q Global: $r=.38, p<.001$ ), EDE-Q Restraint $(r=.25, p=.01)$, EDE-Q Eating Concern $(r=.34, p=.001)$, EDE-Q Shape Concern $(r=.38, p<$ $.001)$, EDE-Q Weight Concern $(r=.45, p=.001)$, anxiety (RCADS Anxiety: $r=.39, p<.001)$, and depression (RCADS Depression: $r=.38, p<.001$ ) among patients.

\section{Discussion}

Consistent with prior research, $40 \%$ of patients with AN or AAN in our study had a history of overweight/obesity, were more likely to present for treatment at a higher \%mBMI and experienced a greater percent weight loss than patients with premorbid normal weights $[2-4,7]$. In line with our hypotheses, adolescents with AN/AAN and premorbid overweight/obesity endorsed greater ED severity on the EDE-Q Global scale and the EDE-Q Restraint, Weight Concerns, and Shape Concerns subscales, and greater psychological morbidity on measures of anxiety and depression. These unique findings were independent of WS and diagnosis (AN or AAN), suggesting that among adolescents with AN/AAN, premorbid weight status may be a strong indicator of illness severity and psychological morbidity.

It is well documented that psychological comorbidity is common in AN/AAN $[44,45]$ yet individuals with overweight/obesity are also at heightened risk for depression and anxiety, low self-esteem, and poorer 
quality of life [46]. Our findings suggest that adolescents with AN/AAN and a history of overweight/obesity may struggle with greater psychological morbidity than premorbid normal weight patients, plausibly reflecting an additive effect, with pre-existing mental health difficulties exacerbating upon ED development and exceeding those experienced among patients with premorbid normal weights.

In line with prior findings [29, 31, 32], weight-based teasing and parent weight talk were positively associated with ED symptoms, anxiety, and depression among all adolescents in our sample. Compared to patients with premorbid normal weights, those with premorbid overweight/obesity reported more frequent weight teasing by peers and a greater frequency of parent comments about their own weights, which could partially account for higher ED symptom severity and psychological distress among this subset of adolescents in our study. Indeed, a dose-response relationship has been demonstrated with weight stigma and psychological distress [31]. Of additional interest, we found no significant differences in the frequency of parent weight talk about adolescents' weights or weight-based teasing by parents for premorbid weight status. Community-based research consistently illustrates a greater prevalence of weight-based teasing and parent weight talk among youth with higher BMIs $[26,27]$. As such, it could be that for youth with normal weights who ultimately develop EDs, the frequency of parent comments about youth weights and teasing by family members occur at a similar frequency to youth with overweight/obesity.

Consistent with the genetic underpinnings of weight status [47], parents of adolescents with premorbid overweight/obesity in our study had significantly higher BMls than parents of patients without a history of overweight/obesity and engaged in more weight talk about their own weights. This suggests that parent BMI may indirectly increase ED risk via parent weight talk, potentially placing youth with higher BMIs at greater vulnerability for this phenomenon.

It is noteworthy we found no significant differences in illness duration for premorbid weight status, suggesting that adolescents in our sample presented for care in a similar time frame, regardless of premorbid weight status. This finding is inconsistent with some published studies that have illustrated greater treatment delays among adolescent patients with premorbid overweight/obesity $[4,5,8]$, yet is consistent with a study by Kennedy and colleagues [2] that illustrated commensurate illness durations in an adolescent sample of inpatients and outpatients with AN/AAN, regardless of premorbid weights. In our sample, approximately $72 \%$ of patients were hospitalized for medical complications of AN/AAN at intake, many of whom were directly admitted from community pediatricians and/or following emergency department visits for objective medical concerns (e.g., syncopal episodes). Upon admission, many patients and caregivers describe feeling "blindsided" by the ED diagnosis, unlike adolescents and caregivers who self-initiate ED treatment for problematic eating behaviors. As such, our finding that illness duration was consistent across patients with AN/AAN, regardless of premorbid weight status, could reflect diverse avenues for entering treatment (e.g., self-initiated versus medically necessitated) and warrants further examination.

We also found no impact of WS on ED symptomatology or psychological distress in our sample, inconsistent with prior studies in adults with EDs $[13,14]$. Further, whereas patients with premorbid overweight/obesity in our sample had a greater percent weight loss than patients with premorbid normal 
weights, we were surprised to find no significant differences in WS across groups. It is noteworthy that methodological challenges in the calculation of WS have been described $[48,49]$ and existing studies about WS are primarily with adult samples. As such, WS may be a construct that is less accessible for research with adolescents given complexity with idiographic growth trajectories and mixed methods in calculating WS. Regardless, further studies examining the relation between WS, ED symptoms, and psychological morbidity among adolescents with EDs are warranted.

Our study includes several limitations. First, underlying mechanisms in the relationship between weight teasing, parent weight talk, ED symptoms, and psychological morbidity were not assessed. Research suggests that internalized weight bias, thin-ideal internalization, and maladaptive coping responses could mediate the relationship between weight stigma, disordered eating, and mental health symptoms [50 - 52]. Future research in this domain is warranted, particularly in comparing adolescents with AN/AAN across premorbid weight classes. Second, beyond weight teasing and parent weight talk, a comprehensive assessment of patients' weight-related experiences could shed further light on the relationship between premorbid weight status, ED severity, and psychological morbidity, including involvement in school-based obesity interventions, prior encouragement to lose weight by parents, providers, and/or mentors, health concerns about potential consequences of overweight/obesity, family eating behaviors, and parent weight history. Third, although our findings illustrate significant associations between the frequency of weight stigma and symptom severity in adolescents with AN/AAN, our cross-sectional design prevents us from supporting causal relationships about these variables. Further, upon controlling for various factors, including sex, care status, and WS, power was diminished. Future studies should include greater sample sizes to ensure greater power and to reduce the risk of Type II errors.

Despite these limitations, findings from our study offer novel and important insights about the subset of adolescents with AN/AAN and premorbid overweight/obesity and guide the following considerations. Foremost, widespread education about the prevalence of AN/AAN among adolescents with premorbid overweight/obesity is imperative to raise awareness, facilitate timely diagnosis and treatment, and to drive distinct prevention efforts. Among these patients, routine assessment for and vigilance to signs of anxiety and depression are indicated, as mental health difficulties may be separate and more severe than mood changes commonly associated with malnutrition. Further, thorough assessment of one's historical weight status, weight stigma, weight bias internalization, specific fears associated with weight gain (e.g., health ramifications, social consequences), prior encouragement to lose weight by others (e.g., parents, providers, coaches), family weight-related environment (parent weight talk, family eating behaviors), and parent weight history could offer invaluable insights into environmental contributors of ED development that could maintain symptoms and trigger relapse if left unaddressed. Whereas nutritional restoration is of utmost importance among adolescents with restrictive EDs [53], findings from our study implicate the importance of monitoring and addressing these unique variables as health status improves.

For adolescents with AN/AAN and a history of overweight/obesity, it is likely that dieting behaviors were reinforced via praise and encouragement, decreased health risks, reduced stigma, and greater potential for social acceptance. In this vein, distinct treatment barriers could arise, particularly for patients with AAN who appear to be "healthy." As described by Kimber and colleagues [54], youth with a history of 
overweight/obesity and their parents may hesitate to buy-in to prescribed weight gain, as this may contradict a long history of direct and indirect encouragement to lose weight. In this regard, fears of weight gain may be justified, as returning to one's premorbid weight status of overweight/obesity could realistically propagate weight stigma and increased risks for medical consequences. This may be particularly salient among adolescents with a history of being teased about their weight by peers. Therefore, sensitivity to these concerns is important, as well as emphasis on the determinants of a healthy weight, beyond prescribed BMI values. Further, caregivers are important role models for adolescent body image development; especially as caregivers' own views and comments about their bodies have been predictive of their adolescent's perception of their body shape and weight. As such, it is also important to address the focus on weight and body image among caregivers as a further preventative and therapeutic measure.

\section{What is already known on this subject?}

Compared to youth with anorexia nervosa (AN) or atypical anorexia nervosa (AAN) and premorbid normal weights, patients with premorbid overweight/obesity often experience greater weight loss, commensurate or more severe physical complications, and diagnostic delays.

\section{What does this study add?}

Findings suggest that compared to adolescents with AN/AAN and premorbid normal weights, patients with a history of overweight/obesity are vulnerable to greater illness severity, anxiety, and depression, and a greater frequency of weight teasing by peers and parent comments about their own weights.

\section{Declarations}

Data Availability: The datasets generated during and/or analyzed during the current study are available from the corresponding author on reasonable request.

\section{Declarations}

Funding: Funding for this study was provided by a Clinical Outcomes Research Enhancement award funded through the Division of Behavioral Medicine and Clinical Psychology at Cincinnati Children's Hospital Medical Center.

Conflicts of interest/competing interests: The authors declare that they have no conflicts of interest or competing interests.

Ethics approval: All procedures performed in studies involving human participants were in accordance with the ethical standards of the institutional and/or national research committee (Cincinnati Children's Hospital Medical Center Institutional Review Board, Study ID 2017-2569) and with the 1964 Helsinki declaration and its later amendments or comparable ethical standards.

Consent to participate: Written informed consent was obtained from the parents of all individual participants included in this study. 


\section{References}

1. American Psychiatric Association (2013) Diagnostic and statistical manual of mental disorders, fifth edn. Arlington, VA: Author.

2. Kennedy GA, Forman SF, Woods ER, Hergenroeder AC, Mammel KA et al (2017) History of overweight/obesity as predictor of care received at 1-year follow-up in adolescents with anorexia nervosa or atypical anorexia nervosa. J Adolesc Health 60:674-679.

https://doi:10.1016/j.jadohealth.2017.01.001

3. Lebow J, Sim LA, Kransdorf LN (2015) Prevalence of a history of overweight and obesity in adolescents with restrictive eating disorders. J Adolesc Health 56:19-24.

https://doi:10.1016/j.jadohealth.2014.06.005

4. Meierer K., Hudon A, Sznajder M, Leduc MF, Taddeo D et al (2019) Anorexia nervosa in adolescents: Evolution of weight history and impact of excess premorbid weight. Eur J Pediatr 178:213-219. https://doi:10.1007/s00431-018-3275-y

5. Peebles R, Hardy KK, Wilson JL, Lock JD (2010) Are diagnostic criteria for eating disorders markers of medical severity? Pediatrics 125:e1193-e1201. https://doi:10.1542/peds.2008-1777

6. Whitelaw M, Lee KJ, Gilbertson H, Sawyer SM (2018) Predictors of complications in anorexia nervosa and atypical anorexia nervosa: Degree of underweight or extent and recency of weight loss? J Adolesc Health 63:717-723. https://doi:10.1016/j.jadohealth.2018.08.019

7. Sawyer SM, Whitelaw M, Grange D, Yeo M, Hughes EK (2016) Physical and psychological morbidity in adolescents with atypical anorexia nervosa. Pediatrics 137:e20154080. https://doi:10.1542/peds.2015-4080

8. Steinhausen HC (2009) Outcome of eating disorders. Child Adolesc Psychiatr Clin N Am 18:225-242. https://doi: 10.1016/j.chc.2008.07.013

9. Swenne I (2016) Influence of premorbid BMI on clinical characteristics at presentation of adolescent girls with eating disorders. BMC Psychiatry 16:81. https://doi:10.1186/s12888-016-0788-7

10. Watson TL, Andersen AE (2003) A critical examination of the amenorrhea and weight criteria for diagnosing anorexia nervosa. Acta Psychiatr Scand 108:175-182. https://doi:10.1034/j.16000447.2003.00201.x

11. Accurso EC, Lebow J, Murray SB, Kass AE, Le Grange D (2016) The relation of weight suppression and BMIz to bulimic symptoms in youth with bulimia nervosa. J Eat Disord 4:21. https://doi.org/10.186/s40337-016-0111-5

12. Witt AA, Berkowitz SA, Gillberg C, Lowe MR, Råstam M, Wentz E (2014) Weight suppression and body mass index interact to predict long-term weight outcomes in adolescent-onset anorexia nervosa. $J$ Consult Clin Psychol 82:1207-1211. http://doi.org/10.1037/a0037484

13. Bodell LP, Racine SE, Wildes JE (2016) Examining weight suppression as a predictor of eating disorder symptom trajectories in anorexia nervosa. Int J Eat Disord 49:753-763. https://doi.org/10.1002/eat.22545 
14. Lowe MR, Piers AD, Benson L (2018) Weight suppression in eating disorders: A research and conceptual update. Curr Psychiatry Rep 20:80. https://doi.org/10.1007/s11920-018-0955-2

15. Haines J, Neumark-Sztainer D (2006) Prevention of obesity and eating disorders: A consideration of shared risk factors. Health Educ Res 21:770-782. https://doi:10.1093/her/cyl094

16. Pont SJ, Puhl R, Cook SR, Slusser W (2017) Stigma experienced by children and adolescents with obesity. Pediatrics 140:e20173034. https://doi:10.1542/peds.2017-3034

17. Tan JOA, Corciova S, Nicholls D (2019) Going too far? How the public health anti-obesity drives could cause harm by promoting eating disorders. In Cratsley K, Radden, J (eds) Developments in Neuroethics and Bioethics: Mental Health as Public Health, Academic Press, 235-264.

https://doi:10.1016/bs.dnb.2019.04.009

18. Puhl RM, Himmelstein MS (2018). Weight bias internalization among adolescents seeking weight loss: Implications for eating behaviors and parental communication. Front Psychol 9:2271. https://doi: 10.3389/fpsyg.2018.02271.

19. Ata RN, Thompson JK (2010) Weight bias in the media: A review of recent research. Obes Facts 3:4146. https://doi:10.1159/000276547

20. Eisenberg ME, Carlson-McGuire A, Gollust SE, Neumark-Sztainer, D (2015) A content analysis of weight stigmatization in popular television programming for adolescents. Int J Eat Disord 48:759-66. https://doi:10.1002/eat.22348

21. Goodyear VA, Armour KM, Wood H (2019) Young people and their engagement with health-related social media: New perspectives. Sport Educ Soc 24:673-688.

https://doi:10.1080/13573322.2017.1423464

22. Greenhalgh S (2015) Fat-talk nation: The human cost of America's war on fat. Ithaca, NY: Cornell University Press, New York.

23. Puhl RM, Heuer CA (2009) The stigma of obesity: A review and update. Obesity 17:941-964. https://doi:10.1038/oby.2008.636

24. Puhl RM, Latner JD (2007) Stigma, obesity, and the health of the nation's children. Psych Bull 133:557580. https://doi:10.1037/0033-2909.133.4.557

25. Puhl RM, Suh Y (2015). Health consequences of weight stigma: Implications for obesity prevention and treatment. Curr Obes Rep 4:182-90. https://doi:10.1007/s13679-015-0153-z

26. Berge JM, MacLehose RK, Loth KA, Eisenberg ME, Fulkerson JA, Neumark-Sztainer D (2015) Parentadolescent conversations about eating, physical activity and weight: prevalence across sociodemographic characteristics and associations with adolescent weight and weight-related behaviors. J Behav 38:122-135. https://doi:10.1007/s10865-014-9584-3

27. Neumark-Sztainer D, Falkner N, Story M, Perry C, Hannan PJ, Mulert S (2002) Weight-teasing among adolescents: correlations with weight status and disordered eating behaviors. Int J Obes 26:123-131. https://doi:10.1038/sj.ijo.0801853

28. Pudney EV, Himmelstein MS, Puhl RM (2019) The role of weight stigma in parental weight talk. Pediatric Obes 14:e12534. https://doi:1111/ijpo.12534 
29. Bauer K, Bucchianeri MM, Neumark-Sztainer D (2013) Mother-reported parental weight talk and adolescent girls' emotional health, weight control attempts, and disordered eating behaviors. Eat Disord 1:1-8. https://doi:1186/2050-2974-1-45

30. Keery H, Boutelle K, van den Berg P, Thompson JK (2005) The impact of appearance-related teasing by family members. J Adolesc Health 37:120-127. https://doi.org/10.1016/j.jadohealth.2004.08.015

31. Libbey HP, Story MT, Neumark-Sztainer DR, Boutelle K (2008) Teasing, disordered eating behaviors, and psychological morbidities among overweight adolescents. Obesity 16:S24-S29. https://doi:1038/oby.2008.455

32. Neumark-Sztainer D, Bauer KW, Friend S, Hannan PJ, Story M, et al (2010) Family weight talk and dieting: how much do they matter for body dissatisfaction and disordered eating behaviors in adolescent girls? J Adolesc Health 47:270-276. https://doi:10.1016/j.jadohealth.2010.02.001

33. Center for Disease Control and Prevention (2017) About Child \& Teen BMI. https://cdc.gov/healthyweight/assessing/bmi/childrens_bmi/about_childrens_bmi.html

34. Fairburn CG, Beglin SJ (1994) Assessment of eating disorders: Interview or self-report questionnaire? Int J Eat Disord 16:363-370.

35. Craig M, Waine J, Wilson S, Waller G (2019) Optimizing treatment outcomes in adolescents with eating disorders: The potential role of cognitive behavioral therapy. Int J Eat Disord 52:538-542. https://doi:10.1002/eat.23067

36. Halvorsen I, Reas DL, Nilsen JV, Rø $\emptyset ~(2018)$ Naturalistic outcome of family-based inpatient treatment for adolescents with anorexia nervosa. Eur Eat Disord Rev 26:141-145. https://doi:10.1002/erv.2572

37. Lock L, Darcy A, Fitzpatrick KK, Vierhile M, Sadeh-Sharvit S (2017) Parental guided self-help familybased treatment for adolescents with anorexia nervosa: A feasibility study. Int J Eat Disord 50:11041108. https://doi:10.1002/eat.22733

38. Rienecke RD, Richmond R, Lebow J (2016) Therapeutic alliance, expressed emotion, and treatment outcome for anorexia nervosa in a family-based partial hospitalization program. Eat Beh 22:124-128. https://doi:10.1016/j.eatbeh.2016.06.017

39. Berg KC, Peterson CB, Frazier P, Crow SJ (2012) Psychometric evaluation of the eating disorder examination and eating disorder examination-questionnaire: A systematic review of the literature. Int $\mathrm{J}$ Eat Disord 45:428-438. https://doi:10.1002/eat.20931

40. Chorpita BF, Yim L, Moffitt C, Umemoto LA, Francis SE (2000) Assessment of symptoms of DSM-IV anxiety and depression in children: A revised child anxiety and depression scale. Behav Res Ther 38:835-855. https://doi:1016/S0005-7967(99)00130-8

41. Chorpita BF, Moffitt CE, Gray J (2005) Psychometric properties of the Revised Child Anxiety and Depression Scale in a clinical sample. Behav Res Ther 43:309-322. https://doi:10.1016/j.brat.2004.02.004

42. Piqueras JA, Martín-Vivar M, Sandin B, San Luis C, Pineda D (2017) The Revised Child Anxiety and Depression Scale: A systematic review and reliability generalization meta-analysis. J Affect Dis 218:153-169. https://doi:10.1016/j.jad.2017.04.022 
43. Anderson CB, Bulik CM (2004) Gender differences in compensatory behaviors, weight and shape salience, and drive for thinness. Eat Behav 5:1-11. https://doi:10.1016/j.eatbeh.2003.07.001

44. Bühren K, Schwarte R, Fluck F, Timmesfeld N, Krei M, Egberts K, Feiffer E, Fleischhaker C, Wewetzer C, Herpertz-Dahlmann B (2014) Comorbid psychiatric disorders in female adolescents with first-onset anorexia nervosa. Eur Eat Disord Rev 22:39-44. https://doi:10.1002/erv.2254

45. Ulfvebrand S, Birgegård A, Norring C, Högdahl L, von Hausswolff-Juhlin Y (2015) Psychiatric comorbidity in women and men with eating disorders results from a large clinical database. Psychiatry Res 230:294-299. https://doi:10.1016/j.psychres.2015.09.008

46. Lindberg L, Hagman E, Danielsson P, Marcus C, Persson M (2020) Anxiety and depression in children and adolescents with obesity: a nationwide study in Sweden. BMC Med 18:1-9. https://doi:10.1186/s12916-020-1498-z

47. Nirmala A, Reddy BM, Reddy PP (2008) Genetics of human obesity: An overview. Int J Hum Genet 8:217-226. https://doi:10.1080/09723757.2008.11886032

48. Gorrell S, Reilly EE, Schaumberg K, Anderson LM, Donahue JM (2019) Weight suppression and its relation to eating disorder and weight outcomes: A narrative review. Eat Disord 27:52-81. https://doi:10.1080/10640266.2018.1499297

49. Schaumberg K, Anderson LM, Reilly EE, Gorrell S, Anderson DA, Earleywine M (2016) Considering alternative calculations of weight suppression. Eat Behav 20:57-63. https://doi.org/10.1016/j.eatbeh.2015.11.003

50. Carels RA, Wott CB, Young KM, Gumble A, Koball A, Oehlhof MW (2010) Implicit, explicit, and internalized weight bias and psychosocial maladjustment among treatment-seeking adults. Eat Behav 11:180-185. https://doi: 10.1016/j.eatbeh.2010.03.002

51. O'Brien KS, Latner JD, Puhl RM, Vartanian LR, Giles C, Griva K, Carter A (2016) The relationship between weight stigma and eating behavior is explained by weight bias internalization and psychological distress. Appetite 102:70-76. https://doi:1016/j.appet.2016.02.032

52. Schvey NA, White MA (2015). The internalization of weight bias is associated with severe eating pathology among lean individuals. Eat Behav 17:1-5. https://doi:j.eatbeh.2014.11.001

53. Lock J, Le Grange D (2015). Treatment manual for anorexia nervosa: A family-based approach. Guilford Publications.

54. Kimber M, Dimitropoulos G, Williams EP, Singh M, Loeb KL, et al (2019) Tackling mixed messages: Practitioner reflections on working with adolescents with atypical anorexia and their families. Eat Disord 27:436-452. https://doi:10.1080/10640266.2018.1542888

\section{Tables}

Table 1. Clinical Characteristics among Adolescents with AN/AAN with Premorbid Overweight/Obesity versus Premorbid Normal Weights 


\begin{tabular}{|c|c|c|c|c|c|c|c|}
\hline & $\begin{array}{l}\text { Premorbid } \\
\text { Overweight/Obesity }\end{array}$ & $\begin{array}{l}\text { Premorbid } \\
\text { Normal } \\
\text { Weight }\end{array}$ & Total & $\begin{array}{l}\text { Statistics } \\
\text { (df) }\end{array}$ & $\begin{array}{l}\text { Statistics } \\
\text { Value }\end{array}$ & $\begin{array}{l}95 \% \\
\mathrm{Cl}\end{array}$ & $p$ \\
\hline & $N=43(40.6 \%)$ & $\begin{array}{l}\mathrm{N}=63 \\
(59.4 \%)\end{array}$ & $\begin{array}{l}N= \\
106\end{array}$ & & & & \\
\hline Sex & $n(\%)$ & $n(\%)$ & $n(\%)$ & & & & \\
\hline Female & 32. (35.5) & $58(64.4)$ & $\begin{array}{l}90 \\
(84.9)\end{array}$ & Fisher's & & & .03 \\
\hline Male & $11(68.8)$ & $5(31.2)$ & $\begin{array}{l}16 \\
(15.1)\end{array}$ & & & & \\
\hline Care status & & & & & & & \\
\hline Inpatient & $30(69.8)$ & $46(73.0)$ & $\begin{array}{l}76 \\
(71.7)\end{array}$ & $\begin{array}{l}\text { Chi } \\
\text { Square } \\
\text { (1) }\end{array}$ & 0.13 & & .82 \\
\hline Outpatient & $13(30.2)$ & $17(27.0)$ & $\begin{array}{l}30 \\
(28.3)\end{array}$ & & & & \\
\hline Diagnosis & & & & & & & \\
\hline AN & $10(23.3)$ & $34(54.0)$ & $\begin{array}{l}44 \\
(41.5)\end{array}$ & $\begin{array}{l}\text { Chi } \\
\text { Square } \\
\text { (1) }\end{array}$ & 9.93 & & .002 \\
\hline AAN & $33(76.7)$ & $29(46.0)$ & $\begin{array}{l}62 \\
(58.5)\end{array}$ & & & & \\
\hline & $M(S D)$ & $M(S D)$ & $M(S D)$ & & & & \\
\hline Age (years) & $15.23(1.59)$ & $\begin{array}{l}15.71 \\
(1.38)\end{array}$ & $\begin{array}{l}15.51 \\
(1.48)\end{array}$ & $t(104)$ & 1.66 & $\begin{array}{l}-0.09 \\
1.06\end{array}$ & .10 \\
\hline $\begin{array}{l}\text { Illness } \\
\text { duration } \\
\text { (months) }\end{array}$ & $11.92(9.80)$ & $\begin{array}{l}9.33 \\
(7.96)\end{array}$ & $\begin{array}{l}10.38 \\
(8.80)\end{array}$ & $t(104)$ & 1.49 & $\begin{array}{l}-0.85 \\
6.02\end{array}$ & .14 \\
\hline $\begin{array}{l}\text { Premorbid } \\
\% \mathrm{mBMI}\end{array}$ & $92.74(7.87)$ & $\begin{array}{l}64.99 \\
(15.71)\end{array}$ & $\begin{array}{l}76.25 \\
(18.92)\end{array}$ & $t(104)$ & 10.70 & $\begin{array}{l}22.61 \\
32.90\end{array}$ & $<.001$ \\
\hline $\begin{array}{l}\text { Premorbid } \\
\text { BMlz }\end{array}$ & $1.71(0.55)$ & $\begin{array}{l}0.38 \\
(0.40)\end{array}$ & $\begin{array}{l}0.92 \\
(0.80)\end{array}$ & $t(104)$ & 14.36 & $\begin{array}{l}1.14, \\
1.51\end{array}$ & $<.001$ \\
\hline $\begin{array}{l}\text { \%mBMl at } \\
\text { intake }\end{array}$ & 46.10 (31.17) & $\begin{array}{l}17.26 \\
(16.47)\end{array}$ & $\begin{array}{l}28.96 \\
(27.41)\end{array}$ & $t(104)$ & 24.20 & $\begin{array}{l}19.60 \\
38.07\end{array}$ & $<.001$ \\
\hline $\begin{array}{l}\text { BMlz at } \\
\text { intake }\end{array}$ & $-0.20(1.40)$ & $\begin{array}{l}-1.21 \\
(0.87)\end{array}$ & $\begin{array}{l}-0.79 \\
(1.22)\end{array}$ & $t(104)$ & 4.18 & $\begin{array}{l}0.57, \\
1.44\end{array}$ & $<.001$ \\
\hline $\begin{array}{l}\text { Percent } \\
\text { weight loss }\end{array}$ & $25.44(11.00)$ & $\begin{array}{l}16.40 \\
(7.29)\end{array}$ & $\begin{array}{l}20.07 \\
(9.98)\end{array}$ & $F(1$, & 5.08 & $\begin{array}{l}5.15 \\
12.32\end{array}$ & $<.001$ \\
\hline
\end{tabular}




\begin{tabular}{|llllllll|} 
& \multicolumn{7}{c|}{$103)^{\mathrm{a}}$} \\
$\begin{array}{l}\text { Weight } \\
\text { suppression }\end{array}$ & $1.91(1.24)$ & 1.59 & 1.72 & $t(104)$ & 1.59 & -0.08, & .11 \\
\hline Parent BMI & $30.08(7.20)$ & $(0.83)$ & $(1.03)$ & & & 0.72 & \\
& & 27.18 & 28.41 & $t(104)$ & 2.08 & 0.13, & .04 \\
& & $(6.30)^{\dagger}$ & $(6.81)$ & & & 5.68 & \\
\hline
\end{tabular}

${ }^{\dagger} \mathrm{n}=54$; ${ }^{\mathrm{a}} \mathrm{ANCOVA}$, controlling for illness duration, was performed to assess differences in percent weight loss

Note. $\mathrm{BMIz}=\mathrm{BMI} \mathrm{z}$-score; $\% \mathrm{mBMI}=$ percent median body mass index for age-and-sex

Table 2. ANCOVA Comparing Premorbid Weight Status on ED Symptoms, Anxiety, and Depression after Controlling for Sex, Care Status, and Weight Suppression

\begin{tabular}{|lllllll|}
\hline & $\begin{array}{l}\text { Premorbid } \\
\text { Overweight/Obesity } \\
\text { M (SD) }\end{array}$ & $\begin{array}{l}\text { Premorbid Normal } \\
\text { Weight } \\
\text { M (SD) }\end{array}$ & & & & \\
& & & & & \\
\hline EDEQ Global & $3.79(1.41)$ & $3.28(1.74)$ & 4.19 & .04 & 0.04 & 0.53 \\
\hline EDEQ Restraint & $3.97(1.52)$ & $3.51(1.86)$ & 4.27 & .04 & 0.04 & 0.57 \\
\hline $\begin{array}{l}\text { EDEQ Eating } \\
\text { Concern }\end{array}$ & $3.03(1.40)$ & $2.74(1.64)$ & 1.24 & .27 & 0.01 & 0.19 \\
\hline $\begin{array}{l}\text { EDEQ Shape } \\
\text { Concern }\end{array}$ & $4.45(1.66)$ & $3.71(2.05)$ & 5.13 & .03 & 0.05 & 0.61 \\
\hline $\begin{array}{l}\text { EDEQ Weight } \\
\text { Concern }\end{array}$ & $3.79(1.69)$ & $3.17(1.86)$ & 5.59 & .02 & 0.05 & 0.61 \\
\hline $\begin{array}{l}\text { RCADS Anxiety } \\
\text { RCADS } \\
\text { Depression }\end{array}$ & $59.95(17.24)$ & $48.31(19.21)$ & 9.46 & .003 & 0.09 & 0.86 \\
\hline
\end{tabular}

Note. EDEQ = Eating Disorder Examination Questionnaire; RCADS = Revised Child Anxiety and Depression Scale

Table 3. Frequency of Weight-Based Teasing and Parent Weight Talk for Adolescents with AN/AAN and Premorbid Overweight/Obesity and Adolescents with AN/AAN and Premorbid Normal Weights 


\begin{tabular}{|llllll|}
\hline Premorbid Weight Status & Never & Rarely & Sometimes & Often & Always \\
& $\mathrm{n}(\%)$ & $\mathrm{n}(\%)$ & $\mathrm{n}(\%)$ & $\mathrm{n}(\%)$ & $\mathrm{n}(\%)$ \\
\hline Teasing by peers* & & & & & \\
\hline Overweight/Obesity $(\mathrm{n}=42)$ & $13(30.2)$ & $10(23.3)$ & $14(34.9)$ & $2(4.7)$ & $3(7.0)$ \\
\hline Normal $(\mathrm{n}=63)$ & $40(63.5)$ & $11(17.5)$ & $10(15.9)$ & $2(3.2)$ & $0(0.0)$ \\
\hline Total $(\mathrm{n}=105)$ & $53(50.0)$ & $21(19.8)$ & $25(23.6)$ & $4(3.8)$ & $3(2.8)$ \\
\hline Teasing by parents & & & & & \\
\hline Overweight/Obesity $(\mathrm{n}=43)$ & $33(76.7)$ & $7(16.3)$ & $3(7.0)$ & $0(0.0)$ & $0(0.0)$ \\
\hline Normal $(\mathrm{n}=63)$ & $51(81.0)$ & $8(12.7)$ & $4(6.3)$ & $0(0.0)$ & $0(0.0)$ \\
\hline Total $(\mathrm{n}=106)$ & $84(79.2)$ & $15(14.2)$ & $7(6.6)$ & $0(0.0)$ & $0(0.0)$ \\
\hline Teasing by siblings & & & & & \\
\hline Overweight/Obesity $(\mathrm{n}=40)$ & $26(65.0)$ & $7(17.5)$ & $4(10.0)$ & $3(7.5)$ & $0(0.0)$ \\
\hline Normal $(\mathrm{n}=61)$ & $47(75.8)$ & $8(12.9)$ & $6(9.7)$ & $0(0.0)$ & $1(1.6)$ \\
\hline Total $(\mathrm{n}=101)$ & $73(71.6)$ & $15(14.7)$ & $10(9.8)$ & $3(2.9)$ & $1(1.0)$ \\
\hline Parent talk about patient weight & & & & & \\
\hline Overweight/Obesity $(\mathrm{n}=43)$ & $1(2.3)$ & $6(14.0)$ & $17(39.5)$ & $10(23.3)$ & $9(20.90)$ \\
\hline Normal $(\mathrm{n}=63)$ & $12(19.0)$ & $15(23.8)$ & $22(34.9)$ & $9(14.3)$ & $5(7.9)$ \\
\hline Total $(\mathrm{n}=106)$ & $13(12.3)$ & $21(19.8)$ & $39(36.8)$ & $19(17.9)$ & $14(13.2)$ \\
\hline Parent talk about parent weight* & & & & & \\
\hline Overweight/Obesity $(\mathrm{n}=43)$ & $1(2.3)$ & $6(14.0)$ & $17(39.5)$ & $10(23.3)$ & $9(20.90)$ \\
\hline Normal $(\mathrm{n}=63)$ & $12(19.0)$ & $15(23.8)$ & $22(34.9)$ & $9(14.3)$ & $5(7.9)$ \\
\hline Total $(\mathrm{n}=106)$ & $13(12.3)$ & $21(19.8)$ & $39(36.8)$ & $19(17.9)$ & $14(13.2)$ \\
\hline
\end{tabular}

*Analyses yielded significantly different proportions of weight-based teasing or parent weight talk by premorbid weight status $(p<.05)$ 